ORNL/TM-2017/497

\title{
Down-Selection of Candidate Alloys for Further Testing of Advanced Replacement Materials for LWR Core Internals
}

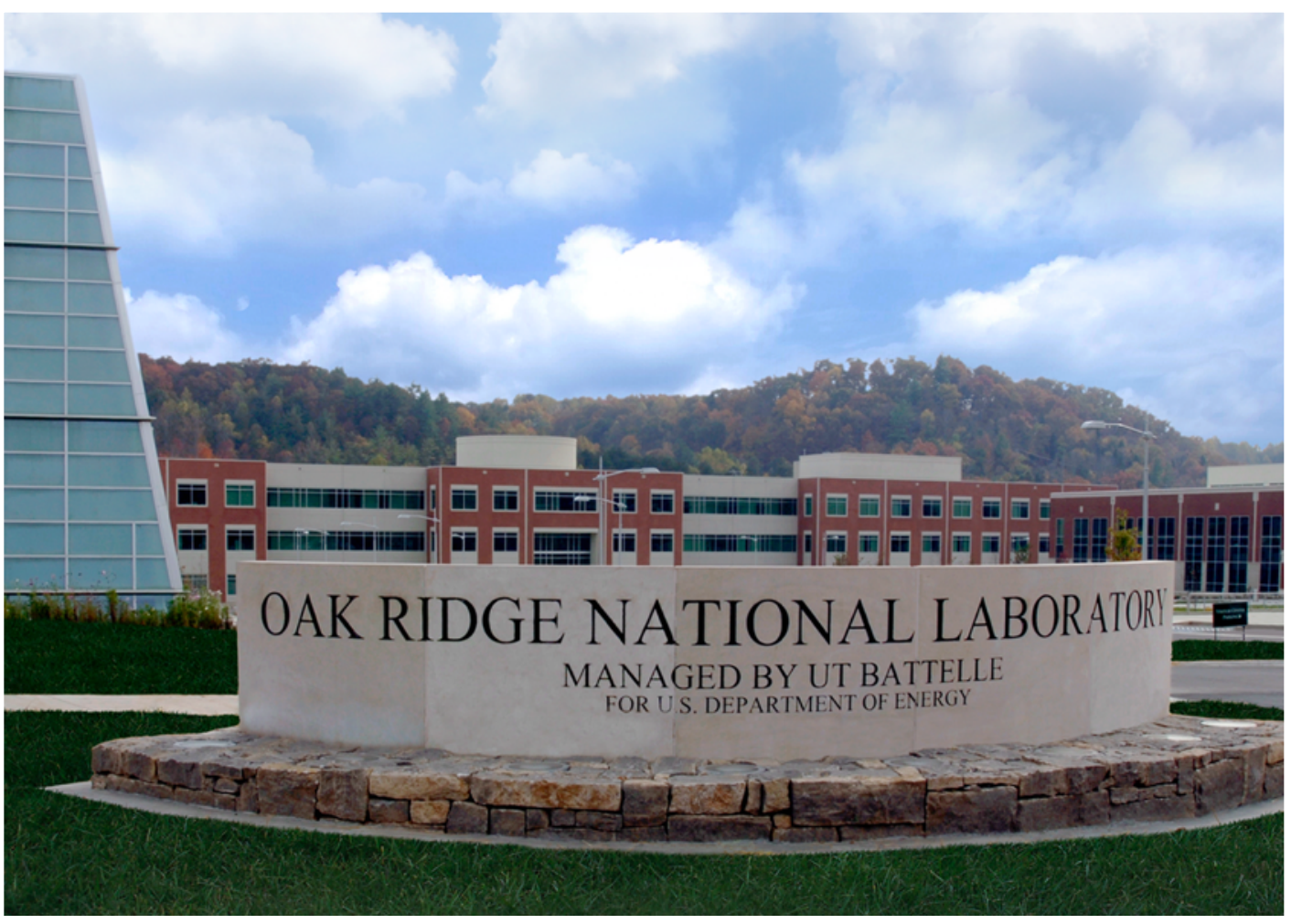

Approved for public release. Distribution is unlimited.
Lizhen Tan (ORNL)

Gary Was (Univ. Michigan) Keith Leonard (ORNL)

September 25, 2017 


\title{
DOCUMENT AVAILABILITY
}

Reports produced after January 1, 1996, are generally available free via US Department of Energy (DOE) SciTech Connect.

Website http://www.osti.gov/scitech/

Reports produced before January 1, 1996, may be purchased by members of the public from the following source:

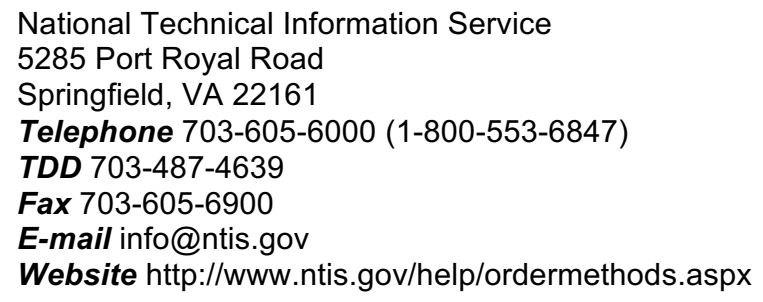

Reports are available to DOE employees, DOE contractors, Energy Technology Data Exchange representatives, and International Nuclear Information System representatives from the following source:

Office of Scientific and Technical Information

PO Box 62

Oak Ridge, TN 37831

Telephone 865-576-8401

Fax 865-576-5728

E-mail reports@osti.gov

Website http://www.osti.gov/contact.html

\begin{abstract}
This report was prepared as an account of work sponsored by an agency of the United States Government. Neither the United States Government nor any agency thereof, nor any of their employees, makes any warranty, express or implied, or assumes any legal liability or responsibility for the accuracy, completeness, or usefulness of any information, apparatus, product, or process disclosed, or represents that its use would not infringe privately owned rights. Reference herein to any specific commercial product, process, or service by trade name, trademark, manufacturer, or otherwise, does not necessarily constitute or imply its endorsement, recommendation, or favoring by the United States Government or any agency thereof. The views and opinions of authors expressed herein do not necessarily state or reflect those of the United States Government or any agency thereof.
\end{abstract}


Light Water Reactor Sustainability (LWRS) Program

M3LW-17OR0406025

\title{
DOWN-SELECTION OF CANDIDATE ALLOYS FOR FURTHER TESTING OF ADVANCED REPLACEMENT MATERIALS FOR LWR CORE INTERNALS
}

\author{
Lizhen Tan and Keith Leonard \\ Materials Science and Technology Division \\ Oak Ridge National Laboratory \\ Gary Was \\ University of Michigan
}

Date Published: September 25, 2017

Prepared under the direction of the

U.S. Department of Energy

Office of Nuclear Energy

Light Water Reactor Sustainability

Materials Aging and Degradation Pathway

Prepared by

OAK RIDGE NATIONAL LABORATORY

Oak Ridge, Tennessee 37831-6283

managed by

UT-BATTELLE, LLC

for the

US DEPARTMENT OF ENERGY

under contract DE-AC05-00OR22725 



\section{CONTENTS}

Page

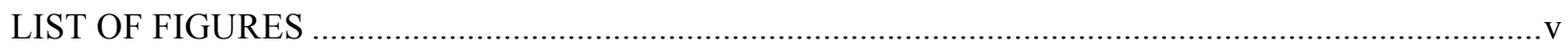

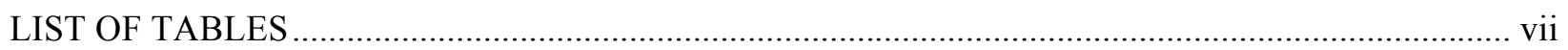

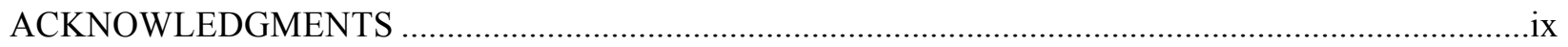

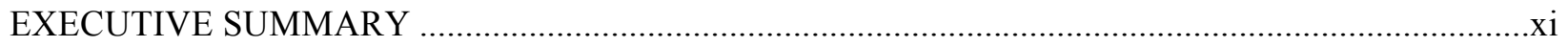

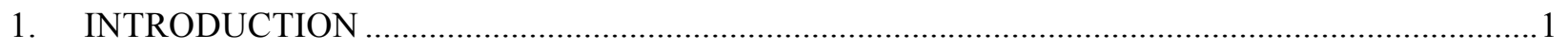

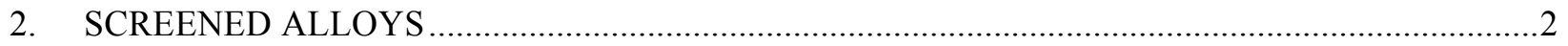

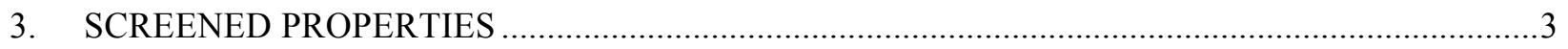

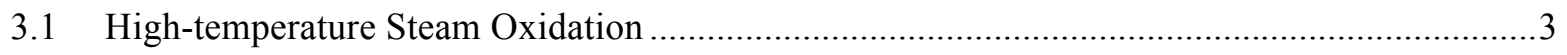

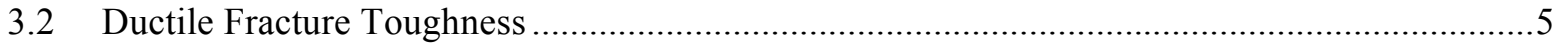

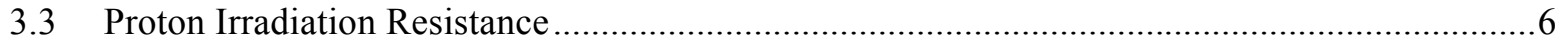

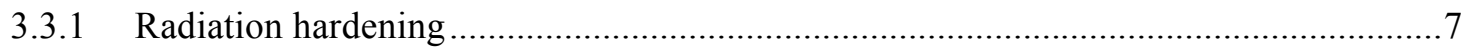

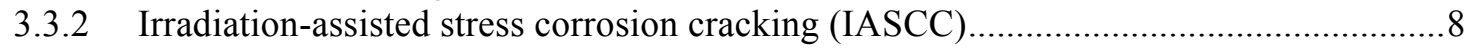

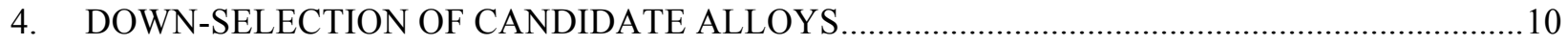

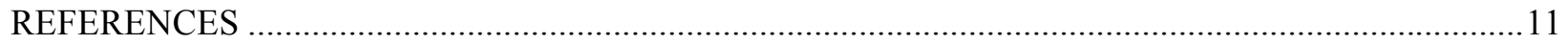





\section{LIST OF FIGURES}

Figure $\quad$ Page

Figure 1. Time-dependent corrosion rate of (a) Grade 92, 14YWT, Alloy 439, and 316L tested at 600 and $650^{\circ} \mathrm{C}$, (b-c) Alloy 800,310 and Ni-base superalloys tested at 600 and $650^{\circ} \mathrm{C} \ldots \ldots \ldots .4$

Figure 2. Corrosion rate of select alloys tested at (a) $600^{\circ} \mathrm{C}$ and (b) $650^{\circ} \mathrm{C}$. (Underline on-going tests; * high-strength alloys)

Figure 3. Temperature-dependent (a) fracture toughness and (b) tearing modulus of the eight tested alloys.

Figure 4. (a) Fracture toughness and (b) tearing modulus averaged within $250-350^{\circ} \mathrm{C}$ for the eight tested alloys. (* high-strength alloys)

Figure 5. Vickers hardness of (a) the irradiated and as-received (AR) alloy samples and (b) the radiation hardening of the select alloys irradiated to $\sim 5$ dpa at $360^{\circ} \mathrm{C}$.

Figure 6. Length ratio between cracks and HAGB in both irradiated and unirradiated areas of (a) low-strength and (b) high-strength alloy samples irradiated to $\sim 5 \mathrm{dpa}$ at $360^{\circ} \mathrm{C}$ and then plastically strained to $\sim 4 \%$ in both BWR NWC and PWR primary water environments. (2 specimens per alloy and condition).

Figure 7. Property ranking of the select alloys on a 0 to 5 scale of best to worst 



\section{LIST OF TABLES}

Table

Page

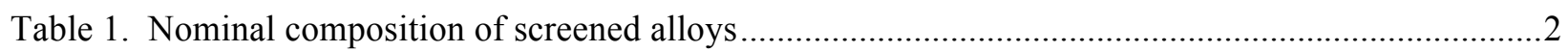

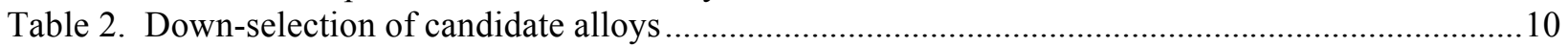





\section{ACKNOWLEDGMENTS}

This research was sponsored by the U.S. Department of Energy, Office of Nuclear Energy, Light Water Reactor Sustainability (LWRS) Program under contract DE-AC05-00OR22725 with UT-Battelle, LLC/Oak Ridge National Laboratory (ORNL). The authors wish to thank the LWRS program providing support for this work, and to Xiang Chen, Eric Manneschmidt and Ron Swain of ORNL and M. Wang and M. Song of University of Michigan for the relevant tests and analyses. The authors are also grateful for the many helpful discussions with Drs. Mikhail Sokolov (ORNL), Raj Pathania (EPRI) and Larry Nelson (JLN Consulting). Dr. Maxim Gussev is appreciated for reviewing the report. 



\section{EXECUTIVE SUMMARY}

Life extension of the existing nuclear reactors imposes irradiation of high fluences to structural materials, resulting in significant challenges to the traditional reactor materials such as type 304 and 316 stainless steels. Advanced alloys with superior radiation resistance will increase safety margins, design flexibility, and economics for not only the life extension of the existing fleet but also new builds with advanced reactor designs. The Electric Power Research Institute (EPRI) teamed up with Department of Energy (DOE) Light Water Reactor Sustainability Program to initiate the Advanced Radiation Resistant Materials (ARRM) program, aiming to identify and develop advanced alloys with superior degradation resistance in light water reactor (LWR)-relevant environments by 2024.

From the initiation of the ARRM program, numerous alloys were evaluated for properties that are favorable for LWR core internal applications. This led to the initiation selection of 15 alloys selected for further testing and evaluation. Corrosion resistance, fracture toughness, and radiation resistance are key engineering properties required for core internal materials. For the 15 select alloys, corrosion resistance was screened using high-temperature steam oxidation tests at 600 and $650^{\circ} \mathrm{C}$. Ductile fracture toughness at $250-350^{\circ} \mathrm{C}$ was evaluated. Radiation resistance was examined by proton irradiation at $\sim 360^{\circ} \mathrm{C}$ followed by constant extension rate tensile (CERT) tests in simulated LWR water conditions and extensive microstructural characterization. Corrosion rate, fracture toughness, tearing modulus, radiation hardening, and irradiation-assisted stress corrosion cracking (IASCC) of the select alloys were obtained and compared to down-select candidate alloys for planned neutron irradiation study and comprehensive postirradiation examinations.

Among the 15 alloys, alloys $\mathrm{Zr}-2.5 \mathrm{Nb}$ (the highest corrosion rate and difficulty in maintaining microstructural control in plate form) and 439 (high ductile-brittle transition temperature and difficult production) were excluded in the first stage. Alloys 625, 625DA, 625plus, 800, and C22 are excluded because of their inferior radiation resistance (e.g., high radiation hardening and mediocre IASCC resistance). Consequently, Grade 92, 316L, 310, 690, X750, 725, 718A, and 14YWT are down-selected candidate alloys for further investigations, among which the former 4 alloys are low-strength alloys and the latter 4 alloys are high-strength alloys, with $316 \mathrm{~L}$ and X750 as reference alloys. 



\section{INTRODUCTION}

Nuclear power currently provides a significant fraction of the United States' non-carbon emitting power generation. In future years, nuclear power must continue to generate a significant portion of the nation's electricity to meet the growing electricity demand, clean energy goals, and to ensure energy independence. New reactors will be an essential part of the expansion of nuclear power. However, given limits on new builds imposed by economics and industrial capacity, the extended service of the existing fleets will also be required.

Nuclear reactors present a very harsh environment for components service. Components within a reactor core must tolerate high temperatures, water, stress, vibration, and an intense neutron field. With the nominal irradiation temperature of $\sim 290^{\circ} \mathrm{C}$ in light water reactors (LWRs), actual component temperatures range from $270^{\circ} \mathrm{C}$ to $370^{\circ} \mathrm{C}$ depending on the relative position of the component within the reactor core and relative amounts of cooling and gamma heating. Degradation of materials in this environment can lead to reduced performance, and in some cases, sudden failure.

Extending the service life of a reactor will increase the total neutron fluence to each component and may result in radiation-induced effects not yet observed in LWR conditions, although this form of degradation has been observed in fast reactor conditions. Radiation-induced processes must be carefully considered for higher fluences, particularly the influence of radiation-induced segregation (RIS), swelling, and/or precipitation on embrittlement. Neutron irradiation field can produce large property and dimensional changes in materials. For LWRs, high-temperature embrittlement and creep are not common problems due to the lower reactor temperature. However, radiation embrittlement, phase transformation, segregation, and swelling have all been observed in reactor components. Increases in neutron fluence may exacerbate radiation-induced or -enhanced microstructural and property changes. Comprehensive reviews on radiation effects on the traditional structural materials of LWRs can be found in Ref. $[1,2,3]$.

It is desirable to have advanced alloys that possess greater radiation resistance than the traditional reactor materials. The use of such advanced alloys in replacing the traditional reactor materials for the extension of the existing fleets and the building of new reactors will bring improved safety margins and economics. To identify and develop advanced radiation resistant materials, Electric Power Research Institute (EPRI) has partnered with Department of Energy (DOE) Light Water Reactor Sustainability Program to conduct an Advanced Radiation Resistant Materials (ARRM) program. The EPRI report of "Critical Issues Report and Roadmap for the Advanced Radiation-Resistant Materials Program" [4] reviewed the current commercial and advanced alloys that are applicable as core structural materials of LWRs and laid out a detailed research plan to meet the goal of the program.

Steam oxidation resistance, fracture toughness, and radiation resistance are key engineering properties required to be screened for the select advanced alloys. Proton irradiation was employed to screen radiation resistance because of its economic advantages and capability of emulating neutron irradiationinduced features to some extent [5]. According to the screened properties, down-selection of the alloys is conducted for neutron irradiation study and comprehensive post-irradiation examinations to understand key factors governing superior properties, from which advanced replacement alloys will be developed and recommended for applications in LWR core internals. This report presents the screening test results of steam oxidation, ductile fracture toughness, and proton-irradiation of select advanced alloys for downselection of the candidate alloys. 


\section{SCREENED ALLOYS}

Table 1 lists the fifteen candidate alloys initially selected to evaluate with respective nominal compositions in weight percentages and heat numbers, which were procured from a variety of vendors or producers, which were selected for screening tests according to Ref. [4]. The materials were examined to have acceptable chemistry homogeneity and microstructural uniformity. According to the type of the materials, they are classified as ferritic steels with a body-centered-cubic (bcc) crystal structure, austenitic stainless steels and nickel-base superalloys with a face-centered-cubic (fcc) structure, together with a zirconium alloy, $\mathrm{Zr}-2.5 \mathrm{Nb}$, with a hexagonal-close-packed (hcp) structure.

Table 1. Nominal composition of screened alloys

\begin{tabular}{|c|c|c|c|c|}
\hline Category & Alloy & Nominal composition & Heat number & Vendor/Producer \\
\hline \multirow{3}{*}{ Ferritic (bcc) } & Grade 92 & $\mathrm{Fe}-9 \mathrm{Cr}-1.8 \mathrm{~W}-0.5 \mathrm{MoVNb}$ & 011448 & Carpenter \\
\hline & 439 & $\mathrm{Fe}-18 \mathrm{Cr}$ & 011438 & Carpenter \\
\hline & $14 \mathrm{YWT}^{*}$ & $\mathrm{Fe}-14 \mathrm{Cr}-3 \mathrm{~W}-\mathrm{TiYO}$ & FCRD-NFA1 & ORNL \\
\hline \multirow{3}{*}{$\begin{array}{l}\text { Austenitic } \\
\quad \text { (fcc) }\end{array}$} & $316 \mathrm{~L}^{\mathrm{a}}$ & $\mathrm{Fe}-16 \mathrm{Cr}-10 \mathrm{Ni}-2 \mathrm{Mo}$ & 857115 & Outokumpu \\
\hline & 310 & $\mathrm{Fe}-25 \mathrm{Cr}-20 \mathrm{Ni}$ & 011509 & Carpenter \\
\hline & 800 & $\mathrm{Fe}-20 \mathrm{Cr}-32 \mathrm{Ni}-\mathrm{TiAl}$ & 07032 & Foroni \\
\hline \multirow{8}{*}{ Ni-base (fcc) } & $718 \mathrm{~A}^{*}$ & $53 \mathrm{Ni}-20 \mathrm{Cr}-17 \mathrm{Fe}-5.2 \mathrm{Nb}-3 \mathrm{MoTiAl}$ & 399 & Carpenter \\
\hline & $725^{*}$ & $58 \mathrm{Ni}-22 \mathrm{Cr}-8 \mathrm{Mo}-8 \mathrm{Fe}-4 \mathrm{NbTi}$ & 416408 & Carpenter \\
\hline & $\mathrm{C} 22$ & $58 \mathrm{Ni}-22 \mathrm{Cr}-14 \mathrm{Mo}-3 \mathrm{~W}-3 \mathrm{Fe}$ & 416270 & Carpenter \\
\hline & 625 & $61 \mathrm{Ni}-22 \mathrm{Cr}-9 \mathrm{Mo}-4 \mathrm{Nb}-4 \mathrm{Fe}$ & 602051 & Carpenter \\
\hline & $625 \mathrm{DA}^{*}$ & 625 direct-aging & JG81 & Allvac \\
\hline & 625 -plus ${ }^{*}$ & $625+\mathrm{Ti}$ & 215846 & Carpenter \\
\hline & 690 & $60 \mathrm{Ni}-30 \mathrm{Cr}-10 \mathrm{Fe}$ & NX7075HK11 & Huntington \\
\hline & $\mathrm{X}-750^{*}$,a & $71 \mathrm{Ni}-16 \mathrm{Cr}-8 \mathrm{Fe}-2.6 \mathrm{TiNbAl}$ & 418365 & Carpenter \\
\hline Others (hcp) & $\mathrm{Zr}-2.5 \mathrm{Nb}$ & $\mathrm{Zr}-2.5 \mathrm{Nb}$ & 251602 & ATI Wah Chang \\
\hline
\end{tabular}

${ }^{*}$ High-strength alloys

${ }^{a}$ Reference alloys

According to the strength of the alloys, they are categorized in two groups as high-strength alloys including X-750, 725, 718A, 625DA (direct-age), 625-plus, and 14YWT [a 14Cr oxide-dispersionstrengthened (ODS) ferritic steel] and low-strength alloys for the rest of the alloys. Alloy X-750 and 316L are included as reference alloys for the high- and low-strength alloys, respectively. 


\section{SCREENED PROPERTIES}

\subsection{High-temperature Steam Oxidation}

Coupons of $19 \times 10 \times 1.5 \mathrm{~mm}$ were extracted from the procured alloys for high-temperature steam oxidation tests in environmental-controlled tube furnaces at 600 and $650^{\circ} \mathrm{C}$ with 1 bar full steam containing $\sim 10$ part-per-billion (ppb) oxygen content. The coupons were polished to a 600 grit SiC finish and cleaned ultrasonically in acetone and methanol prior to the steam tests. Five coupons were tested per alloy with one coupon taken out of the tests after a total of 500,1000, and 2,000 h exposures, which left two coupons reaching the targeted 5,000 h exposures. The coupons were weighted prior to the exposure and after every 500-h exposure using a Mettler-Toledo model XP205 balance with an accuracy of 0.04 $\mathrm{mg}$ or $0.01 \mathrm{mg} / \mathrm{cm}^{2}$. Optical microscopy was employed to characterize the surface morphology and crosssection oxide scales of the exposed coupons that were taken out of the tests. The details of the test can be found in Ref. [6].

Corrosion rate of the alloys was calculated using the equation of $C R(\mathrm{~mm} / \mathrm{year})=87.6 \mathrm{w} / \mathrm{Dt}$, where $\mathrm{w}$ is the measured mass change in $\mathrm{mg} / \mathrm{cm}^{2}, D$ alloy density in $\mathrm{g} / \mathrm{cm}^{3}$, and $t$ exposure time in hours of the tested coupons. Figure 1 plots the time-dependent corrosion rate of the tested alloys. Independent of the weight gains of the ferritic steels or weight losses of 316L, the corrosion rate of the alloys at 600 and $650^{\circ} \mathrm{C}$ tended to be stabilized with the increasing time as shown in Figure 1a. Figure 1b-c indicate that the corrosion rate of Alloys 800,310, and Ni-base superalloys at 600 and $650^{\circ} \mathrm{C}$ were about 2 to 3 orders of magnitudes lower than that of the ferritic alloys and 316L. Except for the ongoing tests of Alloys 310 and $\mathrm{X} 750$, which are to be completed in two months, the corrosion rate of Alloy 800 and Ni-base superalloys tended to be stabilized with time at $600^{\circ} \mathrm{C}$ as shown in Figure 1b. Other than X750, the Ni-base superalloys exhibited different levels of weight losses at $600^{\circ} \mathrm{C}$, with the greatest weight loss for Alloy C22. In contrast, the corrosion rate of the Ni-base superalloys was primarily attributed to weight gains at $650^{\circ} \mathrm{C}$ as shown in Figure $1 \mathrm{c}$, which followed good trends with the parabolic rate law within $\leq 4,000 \mathrm{~h}$, and then decreased in different levels because of the occurrence of exfoliation. 

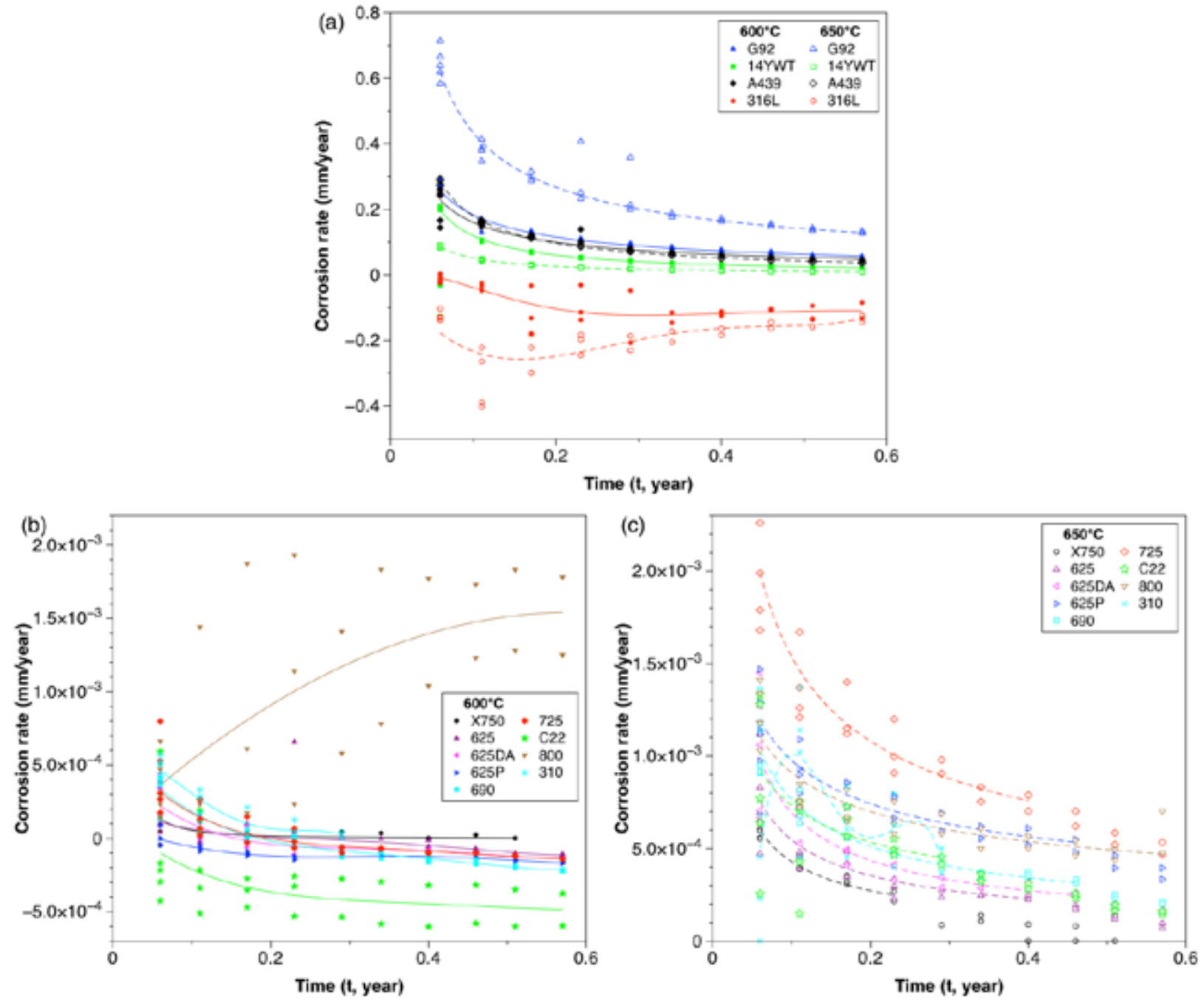

Figure 1. Time-dependent corrosion rate of (a) Grade 92, 14YWT, Alloy 439, and 316L tested at 600 and $650^{\circ} \mathrm{C}$, (b-c) Alloy 800, 310 and Ni-base superalloys tested at 600 and $650^{\circ} \mathrm{C}$.

According to the corrosion rate analysis, the corrosion rate of the alloys tested at 600 and $650^{\circ} \mathrm{C}$ are summarized in Figure 2 using their longest exposure times for comparison. The bar charts are plotted in blue and red for the weight gains (positive) and weight losses (negative) of the results, respectively. The comparison of the $600^{\circ} \mathrm{C}$ data in Figure 2a is likely to be more reliable than that of the $650^{\circ} \mathrm{C}$ data in Figure $2 \mathrm{~b}$ because of the unstable data of the Ni-base superalloys at the longer exposure times as shown in Figure 1c. Alloy $\mathrm{Zr}-2.5 \mathrm{Nb}$ was only tested $500 \mathrm{~h}$ because of their significant oxidation at the two temperatures. In general, $\mathrm{Zr}-2.5 \mathrm{Nb}$ had the worst steam oxidation resistance, followed by $316 \mathrm{~L}$. The steam oxidation resistance of the alloys in an ascending order from the worst to the best would be

1. Worst: $\mathrm{Zr}-2.5 \mathrm{Nb}$ followed by 316L;

2. Moderate: ferritic alloys Grade 92, Alloy 439, followed by 14YWT;

3. Good: Alloy 800, 310, followed by Ni-base superalloys. The Ni-base superalloys exhibited generally comparable steam oxidation resistance, with X750 tended to be the best and C22 to be the worst.

It is expected that the on-going tests of Alloy 310 and X750 will not significantly change the comparison results. 

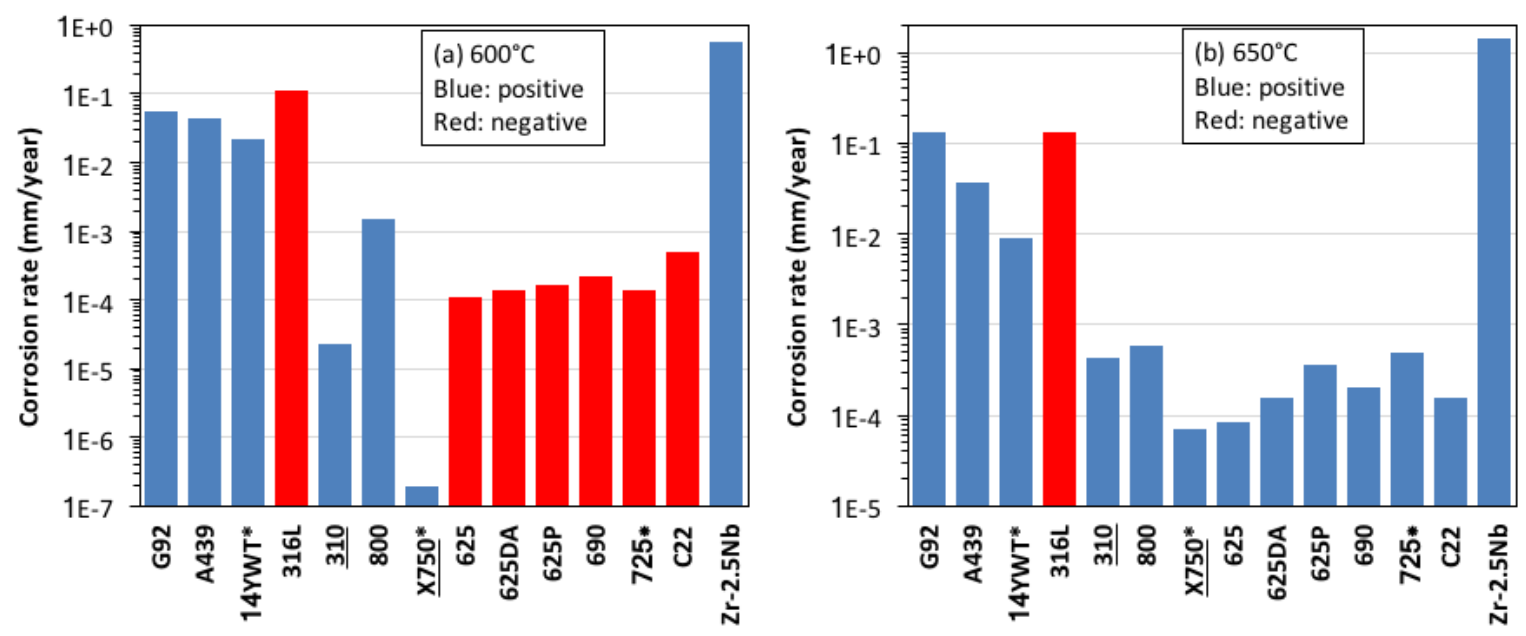

Figure 2. Corrosion rate obtained after 0.5 years exposure of the select alloys tested at (a) $600^{\circ} \mathrm{C}$ and (b) $650^{\circ} \mathrm{C}$. (Underline on-going tests; * high-strength alloys)

\subsection{Ductile Fracture Toughness}

Eight alloys, i.e., Grade 92, 14YWT, 316L, 310, 718A, 725, 690, and X750, were tested using 0.2T compact tension (CT) specimens for the ferritic steels Grade 92 and 14YWT and 0.25T CT specimens for the other alloys. Specimens were machined from the Transverse-Longitudinal (T-L) and RadiusLongitudinal (R-L) orientations for plate and rod product forms, respectively. The tests were conducted in air at room temperature and elevated temperatures of $250,300,350^{\circ} \mathrm{C}$ primarily, in accordance with the ASTM E1820 standard test methods. The test and analysis of the specimens primarily employed the normalization method, complemented with the conventional elastic unloading compliance method. The detailed procedures and results were reported in Ref. [7]. There were seven other alloys selected in screening tests, which include 439, 800, C22, 625, 625DA, 625-plus, and $\mathrm{Zr}-2.5 \mathrm{Nb}$. They are not included in the fracture toughness test matrix because of the observations of some poor performance, e.g., room temperature ductile-brittle transition temperature (DBTT) of alloy 439 [8], poor resistance to irradiation-assisted stress corrosion cracking in alloys 800, 625, 625 direct aging and 625-plus [9], the greatest radiation hardening and poorest resistance to high-temperature steam oxidation of alloy C22 within the Ni-base superalloys [6,9], and the concern of severe accident conditions of $\mathrm{Zr}-2.5 \mathrm{Nb}$ with the poorest resistance to high-temperature steam oxidation among all the select alloys [6].

The analyzed fracture toughness results of the tested eight alloys are plotted in Figure $3 \mathrm{a}$ with $K_{\mathrm{JQ}}$ in logarithmic scale as a function of the test temperatures. It should be noted that the specimens of alloys $316 \mathrm{~L}, 310$, and 690 , except for the two data of alloy 690 at 250 and $350^{\circ} \mathrm{C}$, did not completely comply with plane-strain conditions because the small specimen size could not afford complete plane-strain in such high toughness alloys, which may result in somewhat higher fracture toughness test values. However, they would not prevent the general toughness comparison. In general, the fracture toughness of the austenitic stainless steels and Ni-base alloys were not strongly dependent upon the test temperatures. The alloys exhibited approximately constant or slightly decreased fracture toughness at elevated temperatures. In contrast, ferritic alloys Grade 92 and 14YWT showed slight and significant decreases, respectively, in fracture toughness with the increasing test temperatures.

Tearing modulus, a unitless material parameter accounting for sustained stable crack growth, was calculated in the meantime. Figure $3 \mathrm{~b}$ shows the tearing modulus in logarithmic scale as a function of the test temperatures for the tested alloys. Similar to the major fracture toughness data in Figure 3a, the tearing modulus did not show significant changes within the test temperature range. 

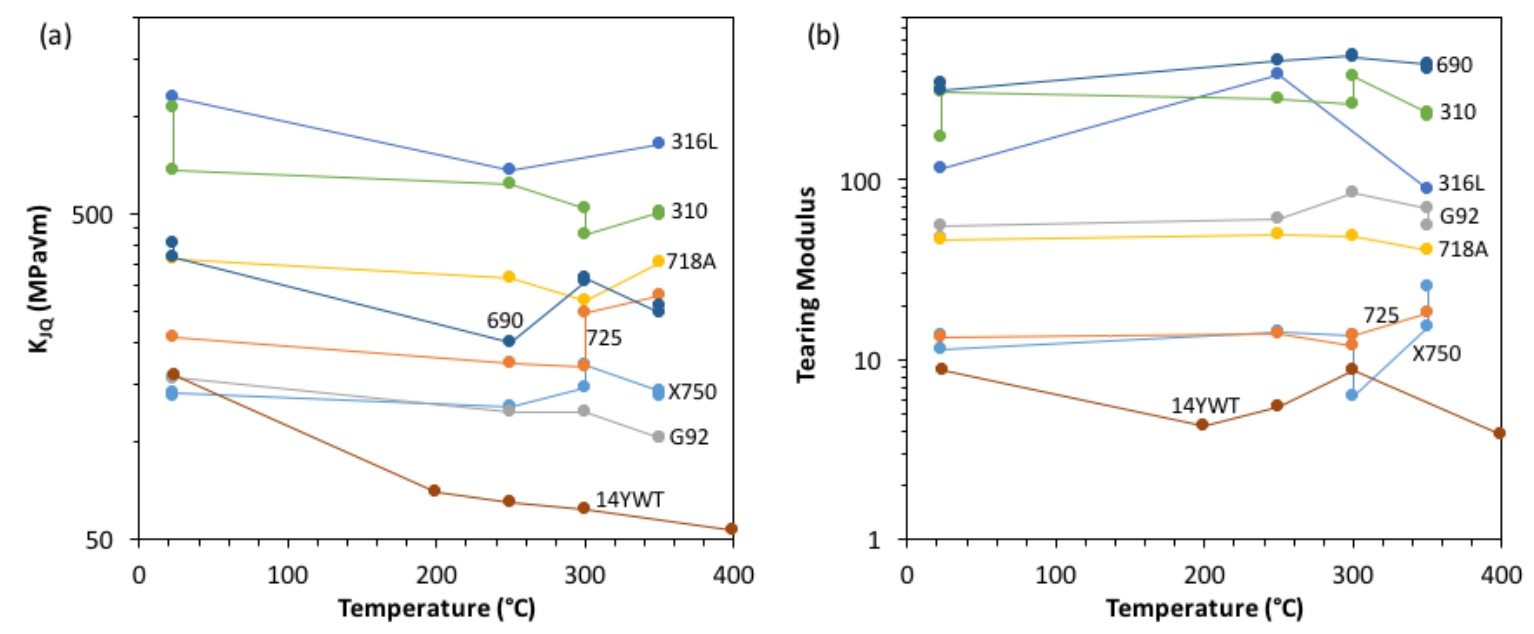

Figure 3. Temperature-dependent (a) fracture toughness and (b) tearing modulus of the eight tested alloys.

The fracture toughness of the alloys at the LWR-relevant temperatures $\left(250-350^{\circ} \mathrm{C}\right)$ was estimated by averaging the toughness values within the temperature range. Figure $4 \mathrm{a}$ shows the average fracture toughness with standard deviations of the alloys, suggesting the fracture toughness of the alloys in a descending order as 316L, 310, 718A, 690, 725, X750, Grade 92, and 14YWT. Similarly, Figure 4b plots the average tearing moduli with standard deviations of the alloys at the LWR-relevant temperatures. Because of the limited statistic data (only two data), alloy $316 \mathrm{~L}$ exhibited a much larger standard deviation than the other alloys. Alloy 690 exhibited the highest tearing modulus on the order of 450 . Austenitic stainless steels 316L and 310 showed somewhat lower tearing moduli on the order of 260. Ferritic alloy Grade 92 had a noticeably lower tearing modulus on the order of 70 . The high-strength alloys 718A, 725, X750, and 14YWT had the lowest tearing moduli, ranging from $\sim 45$ to $\sim 7$.
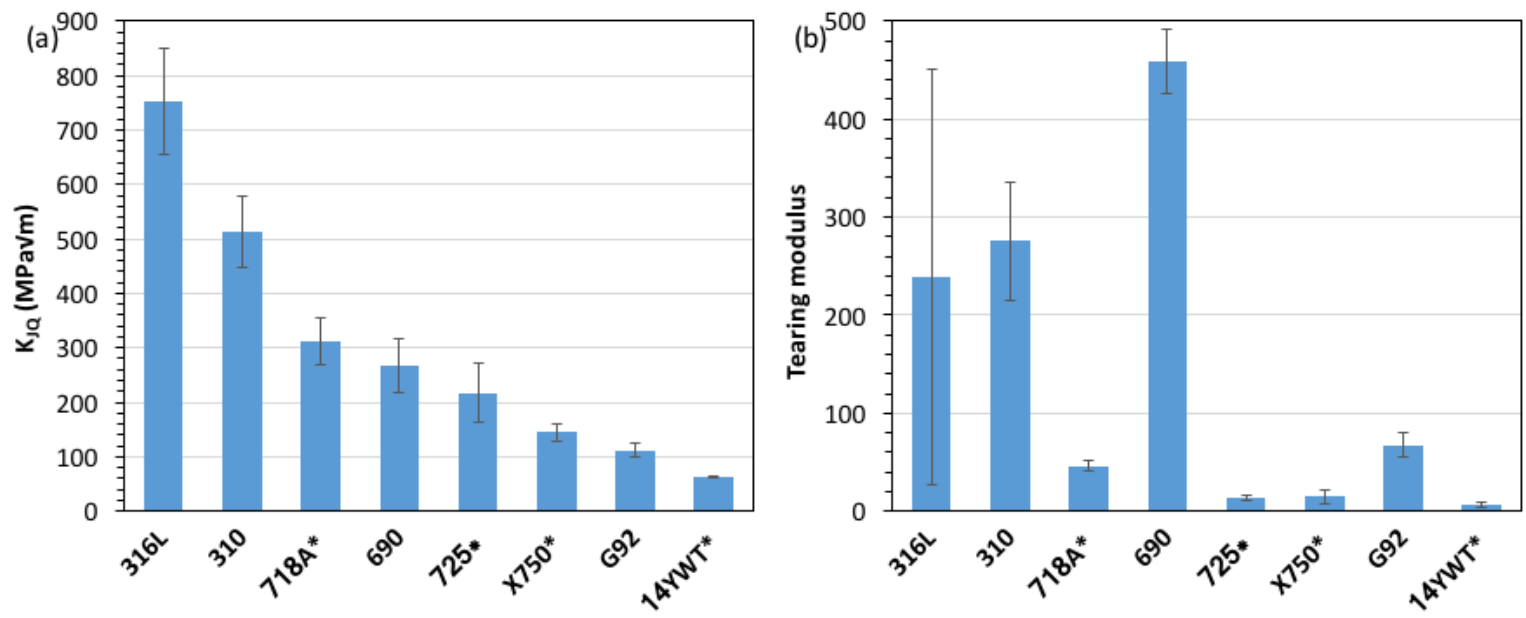

Figure 4. (a) Fracture toughness and (b) tearing modulus averaged within $250-350^{\circ} \mathrm{C}$ for the eight tested alloys. (* high-strength alloys)

\subsection{Proton Irradiation Resistance}

Specially designed samples, e.g., bars of $2 \times 2 \times 20 \mathrm{~nm}$ and tensile samples with a gauge section of 2 $\times 2 \times 21 \mathrm{~mm}$, were extracted from the select alloys and mechanically polished to 4,000 grit using $\mathrm{SiC}$ 
abrasive paper followed by electro-polishing. One of the large surfaces (or gauge surfaces) was irradiated to $\sim 5$ displacements per atom (dpa) at $360 \pm 5^{\circ} \mathrm{C}$ with $2 \mathrm{MeV}$ protons at a dose rate of $\sim 1.3 \times 10^{-5} \mathrm{dpa} / \mathrm{s}$ by using a $3 \mathrm{MV}$ NEC Tandem accelerator in the Michigan Ion Beam Laboratory at the University of Michigan.

Microhardness was measured using a Vickers Hardness indenter (Micromet II) with a load of $25 \mathrm{~g}$, which ensures the plastic zone ahead of the indenter tip within the proton irradiated range $(\sim 20 \mu \mathrm{m})$. Constant extension rate tensile (CERT) tests of the irradiation tensile samples were conducted at a strain rate of $1 \times 10^{-7} \mathrm{~s}^{-1}$ to $\sim 4 \%$ plastic stain in two simulated environments:

- Boiling water reactor (BWR) normal water chemistry (NWC): $288^{\circ} \mathrm{C}, 1,500 \mathrm{psi}, 2,000 \mathrm{ppb}$ dissolved oxygen

- Pressure water reactor (PWR) primary water $(\mathrm{PW}): 320^{\circ} \mathrm{C}, 2,000 \mathrm{psi}, 35 \mathrm{cc} / \mathrm{kg}$ dissolved hydrogen, 1,000 part-per-million (ppm) [B] and 2 ppm [Li]

Extensive microstructural characterization was involved in this study to characterize cracks, grain orientations, grain boundary types, radiation-induced segregation, defects (dislocations and cavities) and phase instability. The detailed experiments and results can be found in Ref. [9]. Here only compares the alloys' performance in terms of radiation hardening and irradiation-assisted stress corrosion cracking (IASCC) resistance.

\subsubsection{Radiation hardening}

Figure 5 plots radiation-induced hardening over the Vickers hardness of the as-received (AR) condition of the examined alloys. Alloy 14YWT is being studied. However, alloy 439 and $\mathrm{Zr}-2.5 \mathrm{Nb}$ were not studied because of the high DBTT and difficulty in production of alloy 439 [8] and worst oxidation resistance of $\mathrm{Zr}-2.5 \mathrm{Nb}$ [8]. The hardness results were averaged from thirty indentation measurements per sample/condition. The results indicate the lowest radiation hardening of $718 \mathrm{~A}$ and Grade 92 in the highand low-strength alloys, respectively. Alloy $\mathrm{C} 22$ exhibited the highest radiation hardening $\left[\Delta \mathrm{H} / \mathrm{H}_{0}=\left(\mathrm{H}_{\text {irr. }}\right.\right.$. $\left.\left.-\mathrm{H}_{0}\right) / \mathrm{H}_{0}\right]$ by $\sim 150 \%$, followed by alloy $310(\sim 110 \%), 316 \mathrm{~L}$ and $800(\sim 90 \%), 690(\sim 75 \%), 625 \mathrm{DA}$ ( 37\%), $625(\sim 29 \%)$, X750 and $725(\sim 23 \%)$, 625plus ( 14\%), Grade $92(\sim 10 \%)$, and 718A $(\sim 1 \%)$.
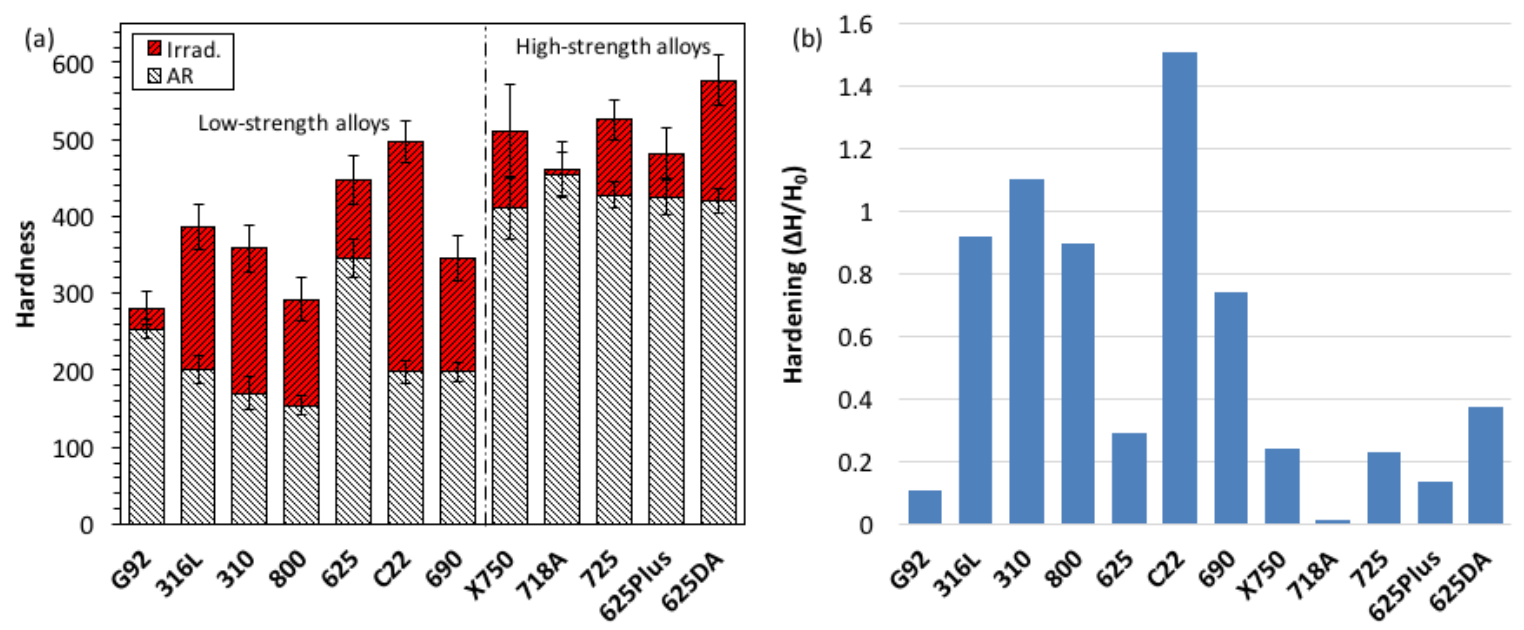

Figure 5. Vickers hardness of (a) the irradiated and as-received (AR) alloy samples and (b) the radiation hardening of the select alloys irradiated to $\sim 5 \mathrm{dpa}$ at $360^{\circ} \mathrm{C}$. 


\subsubsection{Irradiation-assisted stress corrosion cracking (IASCC)}

The length of the cracks $\left(L_{\mathrm{C}}\right)$ within the irradiated area (IA) and unirradiated area (UIA) were characterized, which were compared to the characterized areas $(A)$ and the length of high-angle grain boundaries (HAGB; $\left.L_{\mathrm{HAGB}}\right)$. The quantified $\left(L_{\mathrm{C}} / A\right)_{\mathrm{IA} / \mathrm{UIA}}$ generally showed a similar trend as the $\left(L_{\mathrm{C}} / L_{\mathrm{HAGB}}\right)_{\mathrm{IA} / \mathrm{UIA}}$ for the alloys. Figure $6 \mathrm{a}$ and $\mathrm{b}$ show the $\left(L_{\mathrm{C}} / L_{\mathrm{HAGB}}\right)_{\mathrm{IA} / \mathrm{UIA}}$ results for the low- and highstrength alloys, respectively. Two samples were tested and presented per alloy and test condition.

Grade 92 only had $\sim 2 \%$ plastic strain in the NWC environment because of the appearance of necking, which yielded $0 \%$ cracks within both the IA and UIA. There is no Grade 92 data yet in the PW environment. Such a low uniform plastic strain compared to austenitic and Ni-base alloys is common for ferritic-martensitic steels like Grade 92. The IASCC data of Grade 92 are not able to be quantitatively compared to the other alloys because of the $\sim 2 \%$ plastic strain in Grade 92 compared to $\sim 4 \%$ plastic strain in the other alloys. However, the test results do present the higher IASCC resistance (lower cracking tendency) of Grade 92 compared to the other alloys. Alloy 690 showed excellent IASCC resistance in both the NWC and PW environments. Alloy 800 exhibited the low IASCC resistance with the high cracking tendency in both the NWC and PW environments. Alloy 316L showed poor IASCC resistance in the PW environment, but good resistance in the NWC environment. Similar to Alloys 800 and 316L, Alloy 310 also performed better in the NWC environment compared to in the PW environment, but had less cracking than that in Alloys 800 and 316L. In contrast, Alloy C22 had more cracks in the NWC environment than that in the PW environment. The more cracks of Alloy C22 in the NWC environment might be attributable to the inferior oxidation resistance of $\mathrm{C} 22$ as demonstrated in the steam oxidation results in Figure 1 and 2. The less cracks of Alloy C22 in the PW environment was attributable to the high Mo content in $\mathrm{C} 22$ favoring pitting resistance. Compared to C22, alloy 625 had comparable or worse IASCC resistance, with inconsistent cracking behavior in the PW environment.

The high-strength alloys in Figure $6 \mathrm{~b}$ generally had greater $L_{\mathrm{C}} / L_{\mathrm{HAGB}}$ or worse IASCC resistance than the low-strength alloys in Figure 6a. Similar to C22, the high-strength alloys showed worse IASCC resistance in the NWC environment than that in the PW environment. Alloy 625plus had the worst IASCC resistance, followed by X750 and 718A with comparable moderate IASCC resistance in the NWC environment but the highest IASCC resistance in the PW environment. However, the $L_{\mathrm{C}} / A$ plot presented the worst IASCC resistance of alloy 625DA because of its fine grains $(\sim 12 \mu \mathrm{m})$ compared to the grain size of the other high-strength alloys ranging from $\sim 60$ to $\sim 120 \mu \mathrm{m}$. Alloy 725 showed the best IASCC resistance in the NWC environment but slightly worse IASCC resistance than X750 and 718A in the PW environment. 

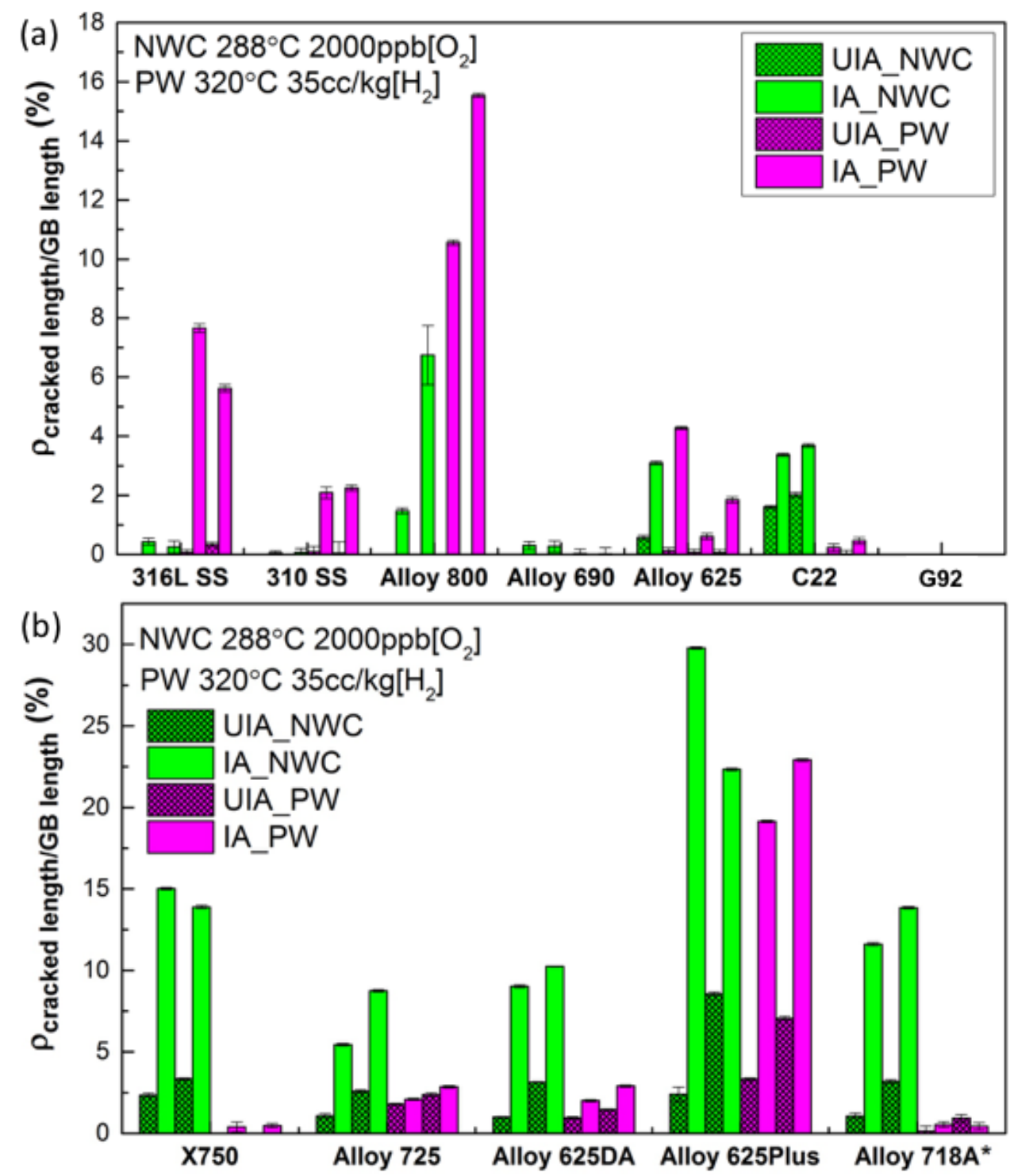

Figure 6. Length ratio between cracks and HAGB in both irradiated and unirradiated areas of (a) lowstrength and (b) high-strength alloy samples irradiated to $\sim 5 \mathrm{dpa}$ at $360^{\circ} \mathrm{C}$ and then plastically strained to $\sim 4 \%$ in both BWR NWC and PWR primary water environments. ( 2 specimens per alloy and condition) 


\section{DOWN-SELECTION OF CANDIDATE ALLOYS}

The examined corrosion rate, fracture toughness, tearing modulus, radiation hardening, and IASCC in NWC and PW of the select alloys are plotted in Figure 7a and b, ranking the properties of the 7 lowstrength and 6 high-strength alloys, respectively, in a 0 to 5 scale of best to worst. The results of each property were normalized to the 0-5 scale for comparison. The 13 select alloys went through steam oxidation tests, radiation hardening and IASCC, except for the radiation properties of 14YWT being characterized. Ductile fracture toughness tests were conducted on 8 of the alloys. According to the results, Table 2 summarizes the down-selection of the candidate alloys with their respective reasoning. The final grade of each alloy by adding its property scores all together $\left(\sum\right)$ could not be obtained because some of the property scores are not available for some of the alloys.
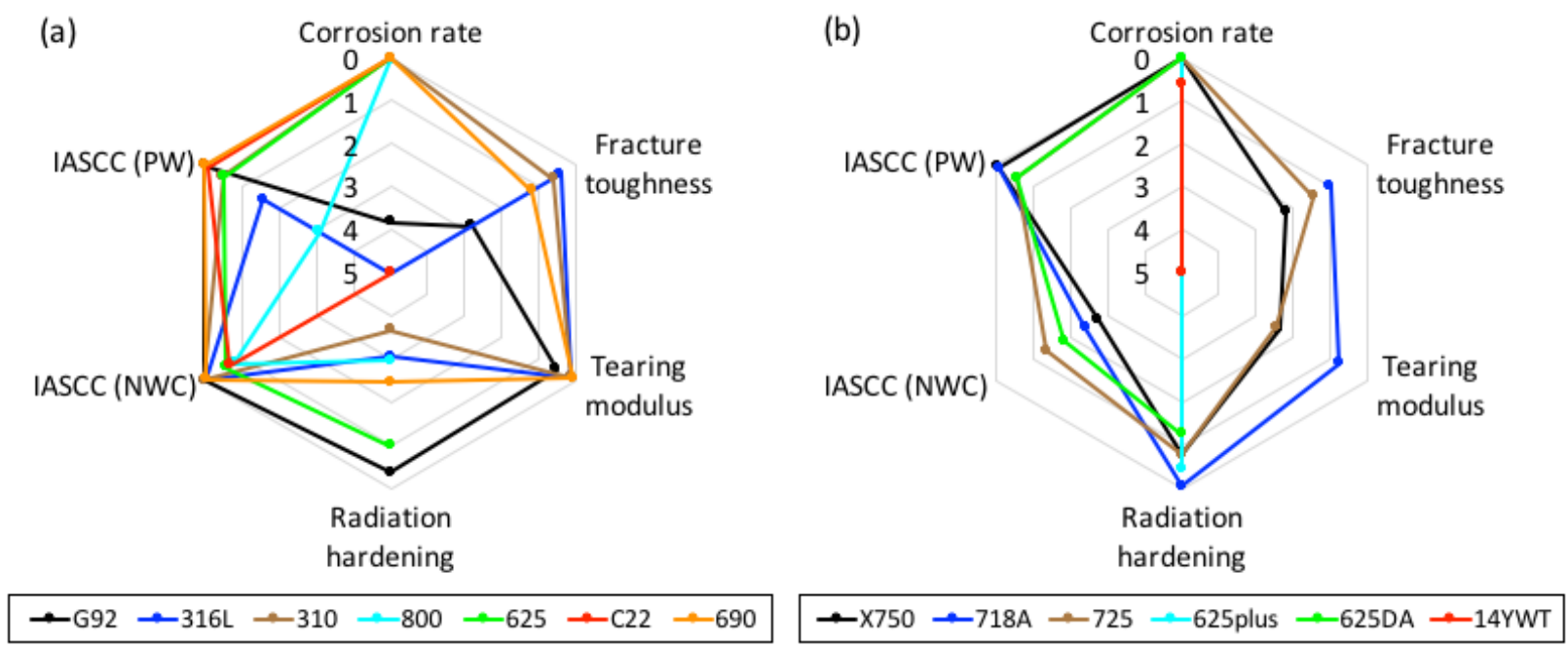

Figure 7. Property ranking of the select alloys on a 0 to 5 scale of best to worst.

Table 2. Down-selection of candidate alloys

\begin{tabular}{|c|c|c|}
\hline Category & Alloy & Remarks \\
\hline \multirow{3}{*}{ Ferritic (bcc) } & Grade 92 & Great radiation resistance despite its inferior corrosion rate and fracture toughness \\
\hline & 439 & High DBTT and difficult production \\
\hline & $14 \mathrm{YWT}^{*}$ & ODS alloy with expected superior radiation resistance despite its poor fracture toughness \\
\hline \multirow{3}{*}{$\begin{array}{l}\text { Austenitic } \\
\quad \text { (fcc) }\end{array}$} & $316 \mathrm{~L}$ & Reference of low-strength alloys \\
\hline & 310 & Superior properties except for radiation-hardening \\
\hline & 800 & High radiation-hardening and poor IASCC in PW \\
\hline \multirow{8}{*}{ Ni-base (fcc) } & $718 \mathrm{~A}^{*}$ & Superior properties \\
\hline & $725^{*}$ & Superior properties \\
\hline & $\mathrm{C} 22$ & The highest radiation-hardening and mediocre IASCC in NWC \\
\hline & 625 & Mediocre radiation-hardening and IASCC \\
\hline & $625 \mathrm{DA}^{*}$ & Inferior radiation resistance \\
\hline & 625-plus* & Inferior radiation resistance \\
\hline & 690 & Superior properties except for radiation-hardening \\
\hline & $\mathrm{X}-750^{*}$ & Reference of high-strength alloys \\
\hline Others (hcp) & $\mathrm{Zr}-2.5 \mathrm{Nb}$ & The highest corrosion rate \\
\hline
\end{tabular}




\section{REFERENCES}

[1] E.A. Kenik, J.T. Busby, Radiation-induced degradation of stainless steel light water reactor internals, Mater. Sci. Eng. R 73 (2012) 67-83.

[2] F.A. Garner, Radiation damage in austenitic steels, in: R.J.M. Konings, T.R. Allen, R.E. Stoller, S. Yamanaka, Comprehensive Nuclear Materials, Elsevier, The Netherlands, 2012.

[3] L. Tan, R.E. Stoller, K.G. Field, Y. Yang, H. Nam, D. Morgan, B.D. Wirth, M.N. Gussev, J.T. Busby, Microstructural evolution of type 304 and 316 stainless steels under neutron irradiation at LWR relevant conditions, JOM 68 (2016) 517-529.

[4] Critical Issues Report and Roadmap for the Advanced Radiation-Resistant Materials Program, EPRI, Palo Alto, CA and the U.S. Department of Energy, Washington, DC: 2012. 1026482.

[5] G.S. Was, Z. Jiao, E. Getto, K. Sun, A.M. Monterrosa, S.A. Maloy, O. Anderoglu, B.H. Sencer, M. Hackett, Emulation of reactor irradiation damage using ion beams, Scripta Mater. 88 (2014) 33-36.

[6] L. Tan, B.A. Pint, High-temperature steam oxidation testing of select advanced replacement alloys for potential core internals, ORNL/TM-2017/228, May 19, 2017.

[7] X. Chen, L. Tan, Fracture toughness evaluation of select advanced replacement alloys for LWR core internals, ORNL/TM-2017/377, August 25, 2017.

[8] L. Tan, B.A. Pint, X. Chen, Toughness and high-temperature steam oxidation evaluations of advanced alloys for core internals, ORNL/TM-2016/371.

[9] G.S. Was, M. Song, M. Wang, C. Lear, IASCC susceptibility and evolution of microstructure in austenitic alloys after proton irradiation, EPRI Report 2017, in preparation. 